\title{
Os circuitos espaciais de produção do petróleo no Rio de Janeiro e em São Paulo: formação e integração da megarregião Rio - SP
}

Roberto Moraes Pessanha e Floriano José Godinho de Oliveira

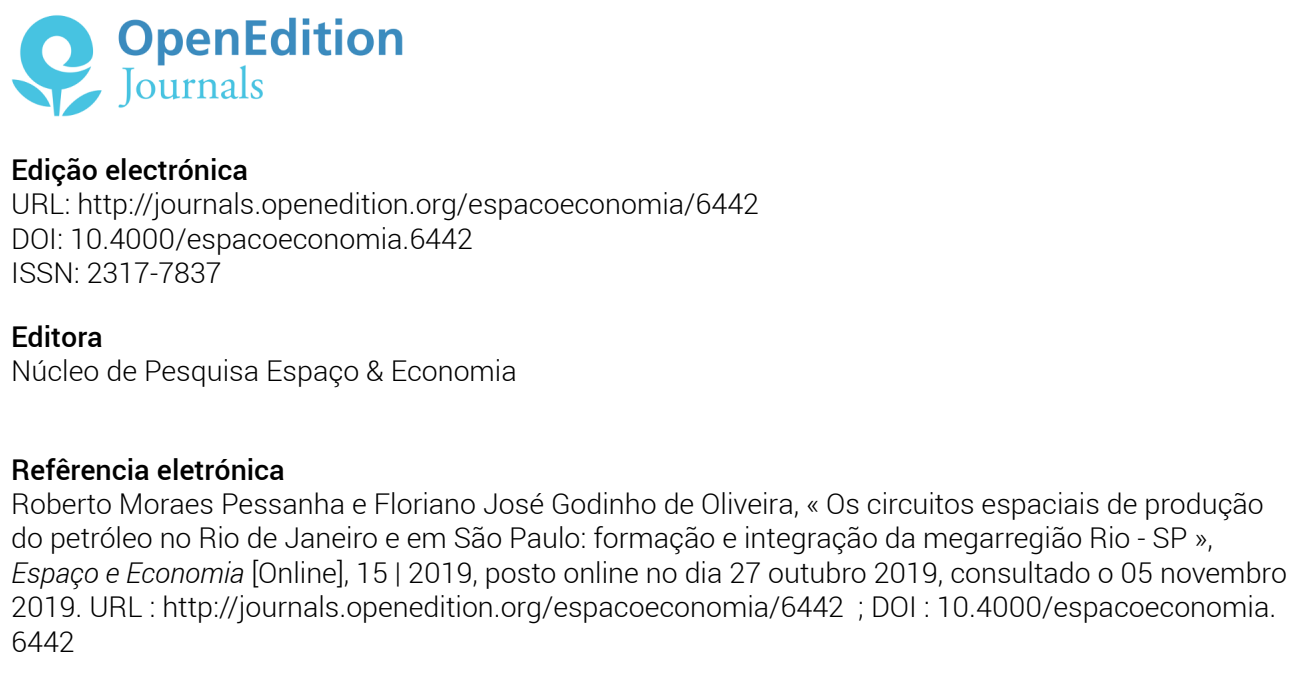

Este documento foi criado de forma automática no dia 5 novembro 2019.

(C) NUPEE 


\section{Os circuitos espaciais de produção do petróleo no Rio de Janeiro e em São Paulo: formação e integração da megarregião Rio - SP}

Roberto Moraes Pessanha e Floriano José Godinho de Oliveira

1 Link para a Revista Geographia, do Programa de Pós-Graduação em Geografia da UFF

2 http://periodicos.uff.br/geographia

3 Link para o artigo

4 http://periodicos.uff.br/geographia/article/view/28276

\section{RESUMO:}

5 A atividade petrolífera de extração, circulação e beneficiamento de petróleo produziu nos estados Rio de Janeiro e São Paulo uma cadeia produtiva que se vertebra por meio de um circuito espacial de produção. Buscamos nesta comunicação uma interpretação sobre como essa fração do capital contribuiu no processo espacial de constituição e expansão da megarregião RJ-SP - tanto em termos do circuito espacial como de sua nebulosa urbana - e as novas formas e arranjos espaciais daí decorrentes. A pesquisa analisa cada uma das estruturas produtivas e redes técnicas estabelecidas no que denominamos Circuito Espacial do Petróleo e dos Royalties nos estados do Rio de Janeiro e em São Paulo, apresentando em mapas as redes formadas pelas bases operacionais e instalações. A partir da interpretação dessas bases busca-se conjugar os fatores dinâmicos da urbanização que nos parece apresentar características cada vez mais regionais e de metropolização do espaço.

6 Palavras-chave: Economia do petróleo. Megarregião. Economia Rio de Janeiro. Circuito espacial da produção. 


\section{Introdução}

7 Este artigo descreve criticamente como o setor de petróleo, representando uma fração do capital, produz e "lubrifica" socialmente o espaço e vem contribuindo para a constituição da megarregião Rio-SP. É uma pesquisa sobre os movimentos do capital, que, por meio do enraizamento no território e da materialidade de suas instalações, reproduz condições para acumulação.

8 Assim, o artigo tem como objetivo inserir na interpretação sobre a constituição e a expansão da megarregião Rio-SP- e sua nebulosa urbana- o papel de integração e adensamento determinado pelos "circuitos espaciais de produção do petróleo e gás" (CEPs) presentes no território, a partir de sua ampla cadeia produtiva (geração de valor), com suas bases industriais, seus eixos de circulação e modais de logística (portos) de distribuição e armazenagem. Propomos, assim, um esforço analítico de recuperação do conceito de "Circuitos Espaciais de Produção" (CEPs), a fim de interpretar, nesse caso, os movimentos das frações do capital (petróleo e logística) e sua influência sobre o processo de metropolização do espaço.

9 A pesquisa procura evidências, no campo da geografia econômica/política (relações de poder) e economia regional, sobre a potência das relações entre os processos, as atividades econômicas e as transformações territoriais. Investiga-se um conjunto de instalações físicas, bases operacionais e infraestruturas, constituídas como capital fixo sobre o território e suas conexões com a rede global do setor petróleo. Busca-se a compreensão dos fatores de integração das sub-redes e de como os CEPs podem estar contribuindo para novas formas de urbanização e modos de vida nesses espaços.

10 Partiu-se, assim, da análise sobre o Circuito Espacial do Petróleo e dos Royalties do Estado Rio de Janeiro (CEPR-RJ), incluindo agora observações sobre a identificação e a constituição do Circuito Espacial do Petróleo e dos Royalties do Estado de São Paulo (CEPR-SP). Até aqui, as interpretações reforçam a hipótese de que os fatores e as formas de constituição, organização e expansão desses circuitos levam à integração não apenas entre o CEPR-RJ e o CEPR-SP, mas também, em especial, da megarregião Rio-SP.

11 O relato desta pesquisa destaca como elemento-chave a forte integração- pouco percebida- entre os circuitos e sub-redes que envolvem as bases operacionais e as instalações desta fração do capital, relacionando-a aos processos de urbanização que possuem características mais regionais e de metropolização do espaço, que levam, simultaneamente, ao adensamento e à expansão paulatina dos limites da megarregião Rio-SP. De forma complementar, também se levanta a hipótese de que, no capitalismo contemporâneo, os CEPs contribuem para o desenvolvimento de urbanizações regionais integradas, mas dispersas, que possuem fortes influências na constituição de megarregiões em outras partes do mundo.

12 Na investigação desses fenômenos, utilizam-se várias bases documentais- em sua essência-, além de pesquisas de campo e entrevistas, reportagens de diversas mídias, relatórios de corporações, documentos, dados e indicadores de gestões públicas (Estado) nas diferentes escalas. As observações no campo e, dialeticamente, a análise de dados e indicadores nos municípios e regiões visaram identificar as formas de produção do espaço e de construção do território. Nesse processo, identificou-se a formação de redes urbanas com características mais regionais, sempre interligadas por eixos de circulação mais vinculados aos interesses econômicos e corporativos interpretados como Condições Gerais de Produção (CGP). 
Através da mediação entre a pesquisa empírica de campo e a análise de dados, buscouse uma interpretação mais ampla e de totalidade desse processo reprodutivo do capital, que possui características sistêmicas, transescalares e multidimensionais, chegando-se à formulação da hipótese de que há uma relação de integração entre os CEPR-RJ e os CEPR-SP que contribui para a formação, a expansão e o adensamento da megarregião Rio-SP.

\section{Imagem síntese:}

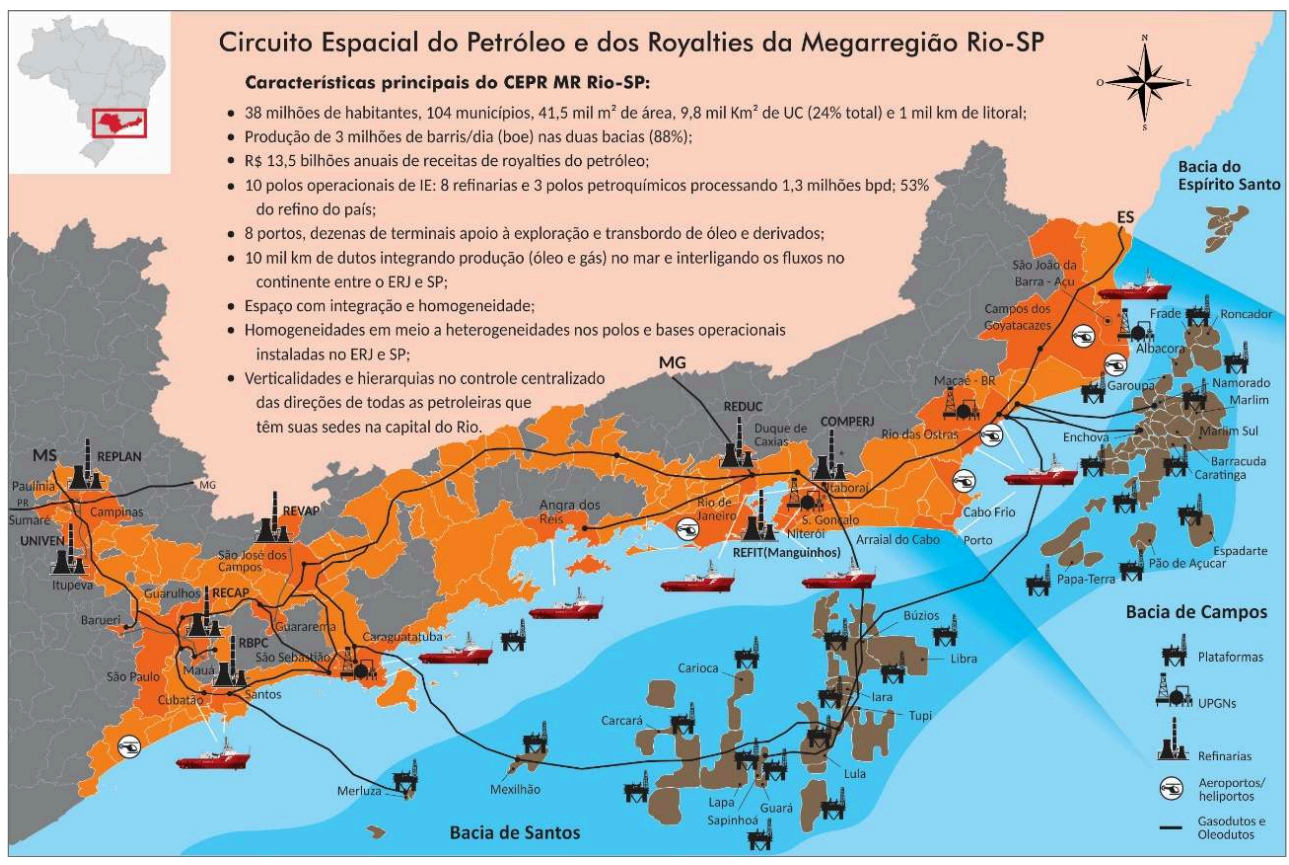

\section{Referências}

ALTVATER, E. 2010. O fim do capitalismo como o conhecemos. Rio de Janeiro: Civilização Brasileira, 1 ed, 364p.

ANP. Agência Nacional de Petróleo. Disponível em: http://www.anp.gov.br. ANUÁRIO FINANÇAS MUNICÍPIOS FLUMINENSES (2015). Ano 8. Aequs. FNP.

ARRIGHI, G. (1997) A ilusão do desenvolvimento. Petrópolis, Ed. Vozes, 371p.

BARRIOS, S. (1986) A construção do espaço. São Paulo: Ed. Nobel, 149p.

BRANDÃO, C. (2009). Território \& Desenvolvimento. Campinas. Unicamp, 238p.

IBGE. (2015) Arranjos Populacionais e Concentrações Urbanas do Brasil. Ed. IBGE, site

LENCIONI, S. (2015) Metropolização do espaço e a constituição de megarregiões. In: FERREIRA, A.; RUA, J.; MATTOS, R. C. (2015) Desafios da metropolização do espaço. Rio de Janeiro: Ed. Consequência, p. 35-68. (a)

LENCIONI, S. Urbanização difusa e a constituição de megarregiões: o caso de São PauloRio de Janeiro. Revista El. Estudos Urbanos e Regionais: Metrópolis, no 22, ano 6, set. 2015. p. 6-15. Observatório da Metrópole. Disponível:< http://emetropolis.net/edicao/n22>. Acesso 19 out. 2016. (b) 
LENCIONI, S. Metrópole, metropolização e regionalização. Rio de Janeiro: Editora Consequência, 2017.

LIPIETZ, A. O capital e seu espaço. São Paulo: Editora Nobel, 1988.

MORAES, A.C. R. Os circuitos espaciais de produção e os círculos de cooperação no espaço. PPG. São Paulo: USP, 1985 (mimeo).

PESSANHA, R. M. A ampliação da fronteira de exploração petrolífera no Brasil é parte da geopolítica da energia. Revista Espaço e Economia-online. Rio ano III, n. 6, 2015 Disponível em: <http://espacoeconomia.revues.org/1511>.

PESSANHA, R.M. A relação transescalar e multidimensional "Petróleo-Porto" como produtora de novas territorialidades. $560 \mathrm{f}$. 2017. Doutorado PPFH-UERJ.

SANTOS, M.. Circuitos espaciais da produção: um comentário. In: BARRIOS, S. A construção do espaço. São Paulo: Editora Nobel, 1986, p.121-134.

SANTOS, M. A Natureza do Espaço. São Paulo: Editora Hucitec, 1996.

SANTOS, M.; SOUZA, M. A.; SILVEIRA, M. L. (Orgs). Território, globalização e fragmentação. São Paulo, Editora Hucitec, 1998.

SANTOS, M. O Espaço Dividido. 2002. São Paulo. Edusp, 2002.

SANTOS, M.; SILVEIRA, M. L. (Orgs). O Brasil: Território e sociedade no início do século XXI. Rio de Janeiro: Editora Record, 2014. (1ª edição: 2001).

SASSEN, Saskia. Toward new urban formats. In: Cities in Schlossplatiz whith Peter Hall, Thilo Sarrazin, Saskia Sassen et al. Berlin: Hertie School of Governance Gmbh, 2008.

SOJA, E.W. Para além de postmetropolis. Revista UFMG, v. 20, n. 1, p. 136-137, jan./jun. 2013.

Site:

Sebrae. $\quad$ https://m.sebrae.com.br/Sebrae/Portal\%20Sebrae/Anexos/ Informacoes\%20sobre\%20a\%20Cadeia\%20Produtiva\%20do\%20Petroleo.pdf

\section{AUTORES}

\section{ROBERTO MORAES PESSANHA}

Instituto Federal Fluminense robertomoraespessanha@gmail.com

FLORIANO JOSÉ GODINHO DE OLIVEIRA

Universide do Estado do Rio de Janeiro - fgodinho@uerj.br 